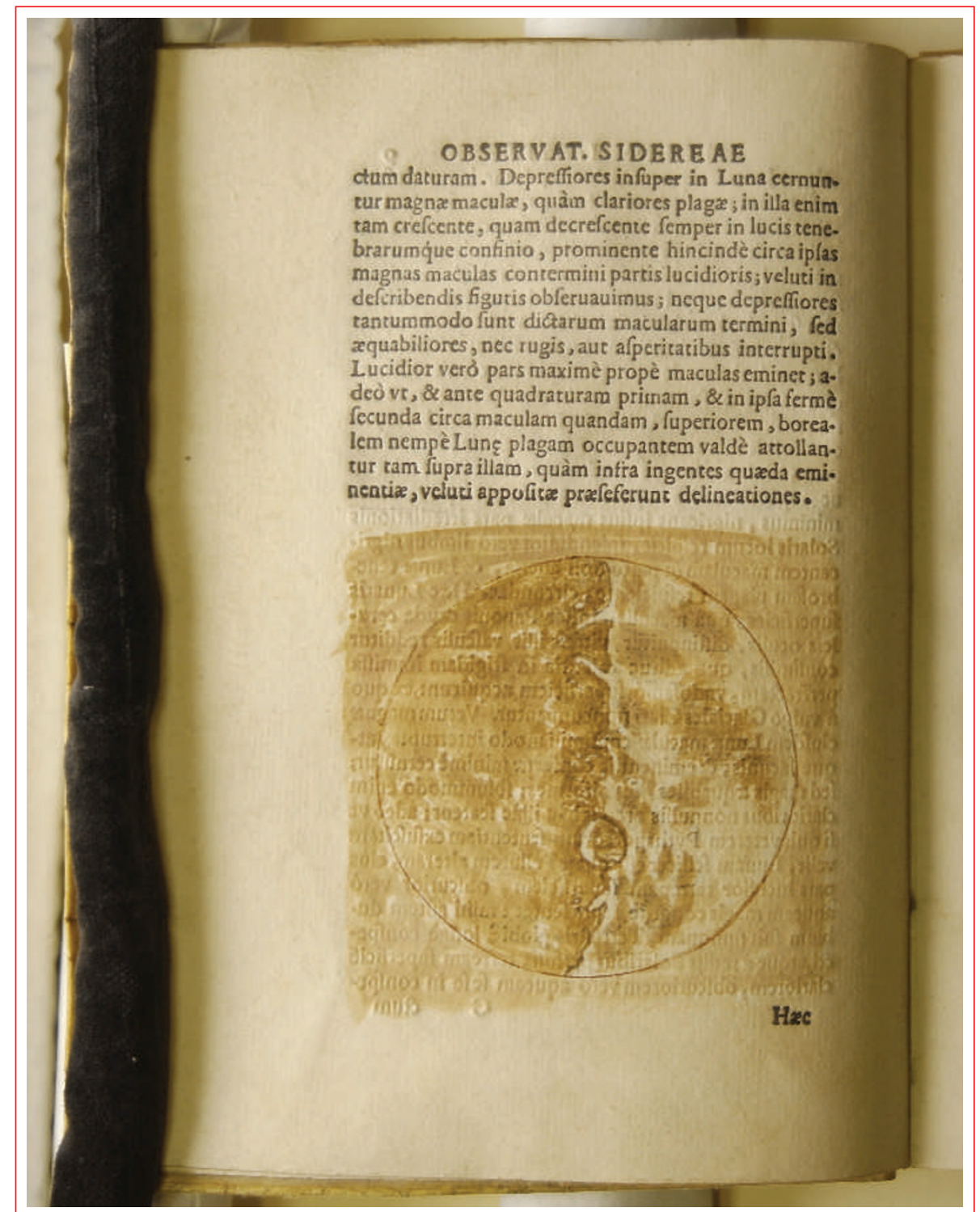

\title{
SNAPSHOT
}

\section{Over the Moon}

Galileo's education included artistic training but his soul was that of a modern scientist: he snapped up new technologies, and was paranoid about being scooped.

When he realized, while pointing his prototype telescope at the Paduan sky, that the Moon was not the smooth, pristine sphere that religious leaders would have us believe, he rushed to publication. His artistic training, reflecting a new awareness of perspective, helped him to understand that the dark spots were shadows thrown by an uneven surface of mountains and craters, and to render this beautifully.

His last observation in his book Sidereus Nuncius (The Starry Messenger) was on 2 March
1610 - one risky day after the Holy Inquisition had approved the text for publication - and 550 copies of the book were ready for distribution to his peers on 12 March. Johannes Kepler received his copy in Prague on 8 April.

Only 500 of those copies included the engravings made from Galileo's famous sketches of the Moon. Now, previously unseen paintings have surfaced in one of the remaining copies, recently acquired in South America by an antiquarian - no doubt a happy man. Last week, art and science historians formally authenticated the five yellowy paintings as being from the hand of Galileo.

Alison Abbott 